\title{
FRUTIFICAÇÃO EFETIVA DA ACEROLEIRA EM CONDIÇÕES OUTONAIS NO MUNICÍPIO DE VIAMÃO-RS, BRASIL
}

\author{
Ruy Inácio Neiva de Carvalbo ${ }^{1}$
}

\section{Resumo}

Este trabalho teve por objetivo avaliar a frutificação efetiva da aceroleira nas condições outonais do Município de Viamão, Rio Grande do Sul, Brasil (30*05'S, 50*47' O, altitude de $52 \mathrm{~m}$ ). Adotou-se o delineamento em parcelas subdivididas em blocos ao acaso com 3 repetições, sendo as parcelas principais os quadrantes norte, leste, sul e oeste da planta e as sub-parcelas 6 épocas de avaliação em intervalos de 8 dias, quando em cada data efetuou-se a contagem do número de frutos em 4 ramos marcados por quadrante avaliado. A frutificação efetiva média foi de 7,49 frutos/100 cachos florais. Ocorreu uma constante queda de acerolas, sendo mais acentuada no início do desenvolvimento dos frutos. O período médio do florescimento à colheita foi de 32,04 dias. A frutificação efetiva e o número de dias para a colheita foram semelhantes nos quadrantes avaliados. Palavras-chave: Acerola, Malpighia glabra L., Queda de frutos, Ciclo de maturação.

\section{Abstract}

This work aimed at evaluating the fruit set of acerola trees in the fall season in Viamão, Rio Grande do Sul, Brazil (30*05'S, 50*47'O, alt. 52m). A split-plot, randomized block experimental design was used, with 3 repetitions. The main plot treatments were plant quadrants (North, East, South and West), and evaluation period used as subtreatment. Six evaluation periods of eight days were adopted, and fruit set of four selected branches per quadrant were quantified daily. Average fruit set was 7,49 fruits per 100-flowers clusters. Fruit drop occured throughout the experimental period, mainly in the initial stages of fruit development. Time from blossom to harvest was similar for all quadrants (32,04 days).

Keywords: Acerola, West Indian Cherry, Malpighia glabra L., Fruit set, Fruit drop, Maturity cycle.

\footnotetext{
${ }^{1}$ Professor de Tecnologia e Análise de Sementes, Centro de Ciências Agrárias e Ambientais, Departamento de Agronomia PUCPR.
} 


\section{Introdução}

A aceroleira (Malpighia glabra L.) é uma espécie frutífera originária de regiões da América Central, noroeste da América do Sul e Antilhas (FOUQUÉ, 1973). Os seus frutos são considerados muito ricos em vitamina $\mathrm{C}$, com teores variando entre 1.000 e $4.676 \mathrm{mg} / 100 \mathrm{~g}$ (LEDIN, 1958).

Embora seja de origem tropical, o seu cultivo é viável em regiões subtropicais, nas quais o período de frutificação concentra-se do final da primavera ao início do outono, alterando a sua característica de produzir frutos ao longo de todo o ano em 4 a 7 florações (JACKSON \& PENNOCK, 1958; BATISTA et al.,1989; MARINO NETO, 1989).

O florescimento natural ocorre em pequenos cachos axilares pedunculados constituídos de 3 a 5 flores que geralmente são auto-polinizadas, porém havendo também a ocorrência de polinização cruzada (COUCEIRO, 1985).

Os agentes polinizadores não estão bem definidos, com citações divergentes em relação à ocorrência de insetos visitando as flores da aceroleira (YAMANE \& NAKASONE, 1961; RAW, 1979; RUBBO \& GASPARETTI, 1985). O vento não foi constatado como eficiente agente de disseminação do pólen (YAMANE \& NAKASONE, 1961).

No clima subtropical do Rio Grande do Sul, as acerolas amadurecem num período médio de 23 dias após a antese (CARVALHO, 1992). Em regiões tropicais, devido às temperaturas elevadas, a frutificação é muito abundante, com a possibilidade de ser incrementada com a utilização de produtos sintéticos como o paclobutrazol (MICHELINI \& CHINNERY, 1989).

A ocorrência de temperaturas entre 25 e $27^{\circ} \mathrm{C}$ e boa insolação, características do clima tropical, possivelmente tem uma relação direta com a alta produção de acerolas (COUCEIRO, 1985). Baixas produções podem estar relacionadas com condições climáticas adversas, polinização ineficiente e irregularidade da biologia floral, como a esterelidade das partes femininas da flor (YAMANE \& NAKASONE, 1961; KUMAR et al., 1981). Segundo Yamane \& Nakasone (1961), não ocorre dicogamia nas flores da aceroleira e o pólen é viável somente no dia da abertura da flor.

Em vista destas considerações, este trabalho tem o objetivo de avaliar a frutificação efetiva da aceroleira em condições outonais, no Município de Viamão-RS.

\section{Material e métodos}

O experimento foi realizado em aceroleiras propagadas por semente e cultivadas no município de Viamão-RS, na grande Porto Alegre, a uma latitude de 30*05'Sul, longitude de 50*47'Oeste e altitude de 52m (FORTES, 1959).

Foi adotado o delineamento em parcelas subdivididas em blocos ao acaso com 3 repetições e uma planta por bloco. Cada aceroleira foi dividida em 4 quadrantes, formando os 4 tratamentos da parcela principal: quadrante norte, leste, sul e oeste. Considerou-se como sub-parcela as diferentes épocas de contagem de frutos em intervalos de 8 dias após o florescimento, totalizando 6 épocas.

$\mathrm{Na}$ ocorrência do pico do florescimento, observado na metade de abril, foram marcados em cada planta 4 ramos por quadrante. Em cada quadrante foi contado o número de cachos florais, totalizando, em média, 150 cachos/quadrante. Em intervalos regulares de 8 dias efetuou-se a contagem de frutos nos ramos marcados e a frutificação efetiva foi calculada em número de frutos por 100 cachos florais. Os cachos surgidos após a contagem inicial foram eliminados manualmente.

A colheita foi efetuada à medida que as acerolas amadureciam e, ao final da frutificação, calculou-se a média de dias para a maturação.

Os dados foram submetidos à análise estatística e as médias foram comparadas pelo teste de Tukey, ao nível de 5\% de probabilidade.

\section{Resultados e discussão}

O número de frutos formados 8 dias após o florescimento foi da ordem de 122 frutos/100 cachos florais, implicando num vingamento de mais de um fruto por cacho. Aos 16 dias do florescimento ocorreu acentuada queda de acerolas, pois mantiveram-se na planta apenas 47,4 frutos/100 cachos florais. Nesse período, as temperaturas médias oscilaram entre 16,5 e $22^{\circ} \mathrm{C}$, abaixo das temperaturas ideais ao desenvolvimento, entre 25 e $27^{\circ} \mathrm{C}$, relatadas por Couceiro (1985), podendo ser um fator que influenciou a queda de frutos.

Uma polinização deficiente ou a ocorrência de irregularidade a nível celular dos órgãos reprodutivos acarretariam numa baixa frutificação efetiva já aos 8 dias após o florescimento, pois não haveria início de formação do fruto. Yamane \& 
Nakasone (1961) observaram no Havaí uma frutificação efetiva entre 1,3 e 11,5\% aos 6 dias após o florescimento, atribuída pela deficiência de polinização. Estes valores foram determinados pelo número de frutos por 100 flores. Considerando-se que um cacho floral é constituído de, em média, 4 flores, as frutificações efetivas encontradas seriam de 5,2 a 47 frutos/100 cachos florais, ainda abaixo das observadas neste estudo (122 frutos/100 cachos).

Uma queda natural de frutinhos é comumente observada em espécies frutíferas, fato desejável em frutificações excessivas para favorecer o desenvolvimento de um menor número de frutos, porém de melhor qualidade, bem como prevenir a ocorrência de alternância de produção em anos consecutivos.

Após o período de uma possível abscisão natural de frutinhos, continuou a ocorrer queda de acerolas com o passar dos dias, em razão principalmente da incidência de baixas temperaturas, que se caracterizaram como um fator limitante ao desenvolvimento do fruto (Figura 1).

A frutificação efetiva média final obtida foi de 7,49 frutos/100 cachos florais, sendo semelhante nos 4 quadrantes da planta (Quadro1).

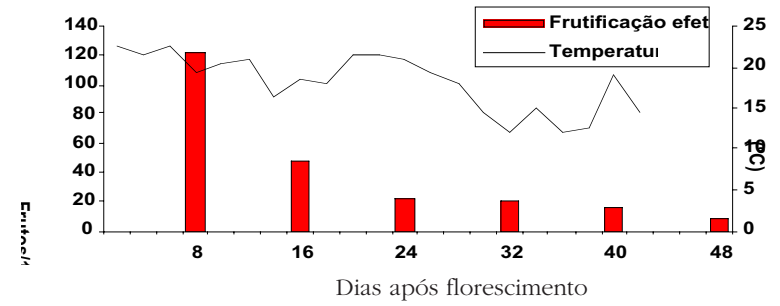

Figura 1: Frutificação efetiva média de aceroleiras cultivadas em condições outonais no Município de Viamão-RS.

Neste caso, a incidência da luz solar não influenciou o vingamento de frutos, pois devido à elevada latitude da área cultivada, os ramos situados no quadrante norte da planta receberam maior incidência de radiação solar, enquanto os frutos localizados no quadrante sul não estavam expostos à radiação solar direta no início do outono.

Cerca de 50\% dos frutos ainda fixados na planta aos 32 dias após o florescimento não atingiram o estádio maduro, quando a temperatura média do período esteve abaixo de $15^{\circ} \mathrm{C}$.

O número de dias para a colheita de acerolas foi de 32,04 dias, não havendo diferença significativa entre os 4 quadrantes da planta (Quadro 1).

Quadro 1: Frutificação efetiva e número de dias para a colheita de acerolas em condições outonais no Município de Viamão-RS, Brasil.

\begin{tabular}{l|c|c|}
\hline $\begin{array}{l}\text { Quadrante da } \\
\text { planta }\end{array}$ & $\begin{array}{c}\text { Frutificação efetiva média } \\
\text { (frutos/100 cachos florais) }\end{array}$ & $\begin{array}{c}\text { Ciclo médio do } \\
\text { florescimento à } \\
\text { colheita (dias) }\end{array}$ \\
\hline Oeste & $10,11 \mathrm{a}$ & $31,01 \mathrm{a}$ \\
\hline Leste & $7,36 \mathrm{a}$ & $31,23 \mathrm{a}$ \\
Norte & $6,94 \mathrm{a}$ & $33,00 \mathrm{a}$ \\
Sul & $5,53 \mathrm{a}$ & $32,93 \mathrm{a}$ \\
\hline Média & 7,49 & 32,04 \\
\hline
\end{tabular}

Médias seguidas de mesma letra na coluna não diferem estatisticamente pelo Teste de Tukey, a 5\% de probabilidade.

O ciclo obtido foi superior ao encontrado por Carvalho (1992) no mesmo pomar, durante o verão (23 dias), e ao citado por COUCEIRO (1985), de 21 a 22 dias, e Batista et al. (1989), de 27 dias, em clima tropical. Este fato demonstra o prolongamento do ciclo de formação do fruto, em virtude da diminuição progressiva da temperatura ambiente.

Em suma, a produção de acerolas em condições outonais é fraca e o ciclo da floração à colheita é prolongado, em função da ocorrência de baixas temperaturas.

\section{Conclusões}

A frutificação efetiva média em aceroleiras em condições outonais de baixas temperaturas foi de 7,49 frutos/100 cachos florais.

Foi observada uma constante queda de acerolas, mais acentuada no início do desenvolvimento dos frutos.

O período médio do florescimento à colheita dos frutos foi de 32,04 dias.

A frutificação efetiva e o número de dias para a colheita foram semelhantes nos quadrantes norte, leste, sul e oeste da planta.

\section{Referências}

BATISTA, F. A. S., MUGUET,B. R. R., BELTRÃO, A. E. S. 1989. Comportamento e seleção da aceroleira na Paraíba. In: CONGRESSO BRASILEIRO DE FRUTICULTURA, 10, Fortaleza, Anais..., Fortaleza, S. B. F., P.26-32. 1989.

CARVALHO, R. I. N. de. Influência do estádio de maturação e de condições de armazenamento na conservação da acerola (Malpighia glabra 
L.). Porto Alegre, 1992 .143f. Dissertação de Mestrado em Agronomia - Fitotecnia - UFRGS (Faculdade de Agronomia).

COUCEIRO, E. M. Curso de extensão sobre a cultura da acerola. Recife, Universidade Federal Rural de Pernambuco, 1985.

FORTES, A. B. Geografia física do Rio Grande do Sul. Porto Alegre, Globo, 1959.

FOUQUÉ, A. Espécies frutiéres d'Amérique tropicale. Fruits, Paris, v. 28, n. 7/8, p.548-558, 1973.

JACKSON, G. C. \& PENNOCK, W. Fruit and vitamin $\mathrm{C}$ production of five and six-year-old acerola trees. Journal of Agriculture of the University os Puerto Rico, Rio Piedras, v. 42, n. 3, p.196-205, 1958.

KUMAR, R. S., PARTHASARATHY, V. A., SUNDARAM,P.K. Cytological studies in the West Indian Cherry (Malpighia punicifolia L.). Progressive Horticulture, Raniket, v. 13, n. 2, p. 73-76. 1981.

LEDIN, R. B. The Barbados or West Indian Cherry. Gainsville, University of Florida, 1958. (Bulletin 594).
MARINO NETO, L. Acerola. A cereja tropical. São Paulo, Nobel. 1989.

MICHELINI, S. \& CHINNERY, L. E. Enhanced multiple cropping in paclobutrazol-treated acerola. Acta Horticulturae, Wageningen, v. 239, p. 281-284, 1989.

RAW, A. Centris dirrhoda (Anthophoridae), the bee visiting West Indian Cherry flowers (Malpighia punicifolia). Revista de Biologia Tropical, Costa Rica, v. 27, n.2, p. 203-205, 1979.

RUBBO, M. S. \& GASPARETTI,L. A. Fruteiras silvestres e exóticas. Informativo da Sociedade Brasileira de Fruticultura, Itajaí, v. 4, n. 3, p.18-25, 1985.

YAMANE, G. M. \& NAKASONE, H. Y. Pollination and fruit set studies of acerola Malpighia glabra L. in Havaí. Proceedings of the American Society for Horticultural Science, Geneva, v. 78, p.141148, 1961. 